\title{
Capsule Commentary on Ratcliffe et al., "Service and Education: the Association Between Workload, Patient Complexity, and Teaching on Internal Medicine Inpatient Services"
}

\author{
Tyler J. Albert, MD \\ Washington, Seattle, WA, USA. \\ (C) Society of General Internal Medicine (outside the USA) 2018
}

Hospital \& Specialty Medicine, VA Puget Sound Healthcare System, Division of General Internal Medicine, Department of Medicine, University of

$\mathrm{T}$ his study by Ratcliffe et $\mathrm{al}^{1}$ explores the relationship between clinical workload, patient characteristics, and educational outcomes through direct observation of medicine teams at teaching hospitals. The authors found only modest associations between team workload and teaching time. Surprisingly, there was a direct positive correlation between increased patient complexity and higher workloads leading to more time for teaching a broader variety of educational topics. Teaching was largely unscripted and dynamic yet closely followed the ABIM blueprint for core internal medicine content. Interestingly, the authors found increased educational time for unanticipated patient complications that was accompanied by a reciprocal negative educational effect for other patients on the team.

This study contributes to the literature on factors associated with teaching during rounds. Data on bedside rounding could certainly have strengthened this contribution with quantitative and qualitative information on this important educational tool that is declining in practice. $^{2}$ One can surmise that unanticipated patient complications led to more bedside interactions between the patient and medical team, thus explaining the increased educational experiences associated with these events.

As the authors mention, this study may temper concerns that increasing clinical demands have negative effects on teaching during attending rounds. It is encouraging that general medicine wards remain comprehensive teaching venues for core internal medicine content. However, the percentage of rounds actually spent on educational activities continues to dwindle in comparison to prior eras, ${ }^{3}$ which should only serve to bolster our efforts to return to the bedside. ${ }^{4,5}$

Corresponding Author: Tyler J. Albert, MD; Hospital \& Specialty Medicine, VA Puget Sound Healthcare System, Division of General Internal Medicine, Department of Medicine University of Washington, Seattle, WA, USA (e-mail: Tyler.Albert@va.gou).

\section{Compliance with Ethical Standards:}

Conflict of Interest: The author has no conflicts of interest with this article.

\section{REFERENCES}

1. Ratcliffe TA, Crabtree MA, Palmer RF, Pugh JA, Lanham HJ, Leykum LK. Service and education: the association between workload, patient complexity, and teaching on internal medicine inpatient services. J Gen Intern Med. https://doi.org/10.1007/s11606-017-4302-9.

2. Crumlish CM, Yialamas MA, McMahon GT. Quantification of bedside teaching by an academic hospitalist group. J Hosp Med. 2009;4(5):304-7.

3. Priest JR, Bereknyei S, Hooper K, Braddock CH 3rd. Relationships of the location and content of rounds to specialty, institution, patient-census and team size. PLoS One. 2010;5(6):e11246.

4. Gonzalo JD, Chuang $\mathbf{C H}$, Huang G, Smith C. The return of bedside rounds: an educational intervention. J Gen Intern Med. 2010;25(8):792-8.

5. McGee S. A piece of my mind. Bedside teaching rounds reconsidered. JAMA. 2014;311(19):1971-2. 